\title{
Mathematical modeling of two-phase media heat transfer coefficient in air cooled condenser systems
}

\author{
Yanán C. Medina $^{1 *}$, Nislan H. Khandy ${ }^{2}$, Ken M. Carlson ${ }^{3}$, Oscar M.C. Fonticiella ${ }^{1}$, Osvaldo F.C. Morales ${ }^{4}$ \\ ${ }^{1}$ Center of Energy Studies and Environmental Technology, Universidad Central de Las Villas, Cuba \\ ${ }^{2}$ Mechanical \& Aerospace Engineering Department, New Mexico State University, USA \\ ${ }^{3}$ Deparment of Chemical Engineering, University of California, Santa Barbara, USA \\ ${ }^{4}$ Technical Sciences Faculty, Universidad de Matanzas, Cuba
}

Corresponding Author Email: ycamaraza1980@yahoo.com

https://doi.org/10.18280/ijht.360142

Received: 24 July 2017

Accepted: 20 March 2018

Keywords:

equation, Roshenow's correction, condensation, deviation, heat transfer.

\begin{abstract}
This paper presents the results of the continuity of the research process carried out at the Center for Energy Studies, belonging to the Faculty of Technical Sciences of the University of Matanzas, related to the production of dimensionless models for the determination of the mean coefficient of heat transfer by condensation in Air Cooled Condenser systems (ACC), inside straight and inclined tubes. The research consists in analytically obtaining the solution of the differential equation of the velocity profile, considering that the condensation is of the film type, finally the Roshenow empirical condition is combined with the theoretical solution, to generate a numerical expression that allows obtaining with A $15,2 \%$ deviation in 692 tests, a mean value of the heat transfer coefficient by condensation very similar to that obtained with the use of the most referenced model in the literature known and consulted, Chato's empirical model.
\end{abstract}

\section{INTRODUCTION}

In a number of heat transfer processes involving saturated steam, a phase change to the liquid state is experienced by the condensation mechanism. This phenomenon occurs when the steam encounters a surface at a lower temperature, [1-5].

It is known from what has been studied in thermodynamics that when raising the temperature of a liquid to a specific pressure up to the saturation temperature $T_{\text {sat }}$ boiling occurs. Likewise, when the temperature of a steam is reduced to $T_{\text {sat }}$, condensation occurs.

Because under equilibrium conditions the temperature remains constant during a phase change process at a fixed pressure, large amounts of heat can be transferred due to the high latent heat of vaporization $\left(r_{L V}\right)$ released or absorbed during condensation, essentially at constant temperature. However, in practice it is necessary to maintain some difference between the surface temperature $T_{P}$ and $T_{\text {sat }}$ to have an effective transfer of heat. Typically, the heat transfer coefficients $\alpha$ associated with condensation are much higher than those found in other forms of convection processes that relate to a single phase [6-8].

In the overwhelming majority of the available sources consulted, the unified criterion on the use of the Chato expression to obtain the mean heat transfer coefficient by condensation inside of horizontal pipes coincides. However, the Chato equation has as an inconvenience the fact that in its generalization experimental points of different fluids were used, among them water, although the great majority of these correspond to refrigerants. Another drawback of Chato's expression is that it is limited by the speed of the working agent, being valid only for Reynolds numbers less than 35000 , thus avoiding operation in the laminated zone, with the consequent danger of condensation stagnation in the interior of the tube. This drawback is partially eliminated in inclined pipes, if the normal flow and gravitational forces coincide. The Chato equation considers that the steam has a negligible velocity, so it does not influence the heating of the stratified liquid in the bottom of the tube, nor does it exert drag on it.

This problem encouraged the authors to create a calculation methodology that takes into account the effect of steam trapping and liquid subcooling, and is as precise as the most recommended and referenced expression in the specialized literature on the subject [9-12], the Chato equation. To meet this objective, a combination of the differential ratio of the velocity profile inside a tube and the solution of the differential equation of the temperature distribution were made. The theoretical solution obtained is subsequently affected by Roshenow's empirical correction. Although the primary results obtained here are provided, the authors still continue to refine the model in a futuristic attempt to reduce correlation errors with respect to available experimental data and to reduce the mathematical complexity of the relationship obtained.

\section{MATERIALS AND METHODS.}

\subsection{Deduction of an equation for heat transfer coefficient determination in ACC systems}

Heat exchange is a decisive process in the efficiency of the cycle. Approximately $90 \%$ of the heat extracted in a power cycle is done through the condensation system. The waste heat from the steam turbine is released into the atmosphere from the cooling system, which, depending on the 
environmental conditions, makes this exchange from water circulation systems or direct cooling with the environment, [11].

Power plants and in processing industries using ACC systems, condensation is carried out in a bundle of sloped pipes. The float force exerted by the liquid on the tube surface is given by $\left(\rho_{L}-\rho_{V}\right) g \sin \theta$ this is justified because the surface of the tube is not flat but curved and this force of flotation is following the approximation given by a line tangent to the surface of the tube that arises as a result of the trajectory of the upper portion to the lower portion, Section, as shown in figure 1 .

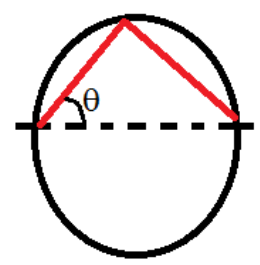

Figure 1. Angle and approximation taken in the present material for the curvature of the tube surface

Therefore, the angle $\theta$ is measured from the top of the tube. The differential equation for the velocity $V(y)$ profile across the film, for any particular value of $\mathrm{x}$, further considering that $\Delta y=0$ it is given by the following expression [13-15]:

$\mu_{L} \frac{\partial^{2} V}{\partial y^{2}}+\left(\rho_{L}+\rho_{V}\right) g=0$

The differential equation (1) is now affected by the term $\sin \theta$ by the presence of the inclination already mentioned in the pipe wall, therefore the expression (4) is transformed and remains as follows [16-17]:

$\mu_{L} \frac{\partial^{2} V}{\partial y^{2}}\left(\rho_{L}-\rho_{V}\right) g \sin \theta=0$

The differential equation (2) is a differential equation of velocity profile, in this case velocity $V(y)$ across the film for any particular value of $\mathrm{x}$. To solve this, two boundary conditions are required. On the wall the non-slip condition of the actual fluid is taken, therefore:

$y=0$ and $V=0$

At the surface of the film it is assumed that the steam drag is minimal. If taken $\delta(x)$ as the thickness of the film, the required contour condition will then be given by:

$y=\delta \quad ; \quad \frac{\partial V}{\partial y}=0$

The thickness of the film $\delta(x)$ is a function yet to be determined. The negligible or negligible entrainment condition of steam is valid on many occasions when the steam velocity is not too great. Integrating the differential equation (2) gives: $\frac{\partial V}{\partial Y}=-\frac{\left(\rho_{L}-\rho_{V}\right) g \sin \theta}{\mu_{L}}+C_{1}=0$

Introducing in equation (5) the boundary condition expressed in expression (4) we have:

$0=-\delta \frac{\left(\rho_{L}-\rho_{V}\right) g \sin \theta}{\mu_{L}}+C_{1}$

By pouring in (6) the integration constant $C_{1}$ and replacing again we have to:

$\frac{\partial V}{\partial Y}=\frac{\left(\rho_{L}-\rho_{V}\right) g \sin \theta}{\mu_{L}}(\delta-y)$

Integrating again, the differential equation (7) yields:

$V=\frac{\left(\rho_{L}-\rho_{V}\right) g \sin \theta}{\mu_{L}}\left(\delta y-\frac{y^{2}}{2}\right)+C_{2}$

Taking the boundary conditions given in (4), by applying them in (8) we obtain that $C_{2}=0$. Reordering the equation (8) we arrive at:

$V=\delta^{2} \frac{\left(\rho_{L}-\rho_{V}\right) g \sin \theta}{\mu_{L}}\left(\frac{y}{\delta}-\frac{1}{2}\left(\frac{y}{\delta}\right)^{2}\right)$

The relation (9) indicates that the velocity profile $V(y)$ is parabolic. The speed will reach a maximum on the surface of the film when $y=\delta$. Substituting this condition into (12), the maximum speed can be determined, which is given by [2], [4], [6]:

$V_{\text {max }}=\delta^{2} \frac{\left(\rho_{L}-\rho_{V}\right) g \sin \theta}{2 \mu_{L}}=\frac{g \delta^{2} \sin \theta}{2 v_{L}} \frac{\left(\rho_{L}-\rho_{V}\right)}{\rho_{L}}$

By establishing a maximum velocity test on the film surface in an inclined tube with the same maximum speed condition for a vertical surface, identical solutions are obtained with the proviso that the first is affected by $\sin \theta$, caused by the curvature of the surface and the inclination of the tubes. The mass flows of condensate per unit width of the film on vertical and inclined surfaces are also identical, [1], [11] and it are remembered that they must be affected by, therefore it is satisfied that:

$G=\frac{\rho_{L}\left(\rho_{L}-\rho_{V}\right) g \delta^{3} \sin \theta}{3 \mu_{L}}=\frac{\rho_{L}\left(\rho_{L}-\rho_{V}\right) g \delta^{3} \sin \theta}{3 v_{L}}$

Therefore the number of $\mathrm{Re}$ of film is given by:

$R e=\frac{4}{3} \frac{\left(\rho_{L}-\rho_{V}\right) g \delta^{3} \sin \theta}{\rho_{L} v_{L}^{2}}$

Considering that the length of the tube is much larger than its diameter, and that the process is assumed to be stationary, then the temperature distribution can be treated in a simplified way as one-dimensional, therefore, according to what is stated in [18-20], the differential equation of temperature distribution is reduced to.

$\delta\left(\partial^{2} T / \partial y^{2}\right)$

Two boundary conditions are required to integrate the differential equation (16). The continuity of the temperature 
at the surface of the film requires that $T=T_{\text {Sat }}\left(T_{\text {sat }}\right)$ is the saturation temperature corresponding to the vapor pressure), therefore the first boundary condition is given by:

$y=\delta \quad ; \quad T=T_{\text {Sat }}$

As a second contour condition, it is assumed that the wall is isothermal at temperature $T_{P}$, therefore:

$y=0 \quad ; \quad T=T_{P}$

Integrating twice the differential equation (13) is given above:

$T=y \cdot C_{1}+C_{2}$

Introducing in (16) the given boundary conditions (14) and (15) gives:

$T-T_{P}=\frac{y}{\delta}\left(T_{S a t}-T_{P}\right)$

The ratio (17) is a linear temperature profile, since the problem is identical to that of conduction through a flat plate. Therefore, the heat flow per unit area towards the wall is simply the flow per unit area through the film:

$\left.\lambda_{L} \frac{\partial T}{\partial y}\right|_{P}=\frac{Q}{F}=\lambda_{L} \frac{\left(T_{S a t}-T_{P}\right)}{\delta}$

The local heat transfer coefficient $\alpha$ is defined as the quotient that exists between the heat flux per unit area and the temperature difference across the film, therefore [8], [10], [11]:

$\alpha=\frac{q}{\left(T_{\text {Sat }}-T_{P}\right)}=\frac{\left.\lambda_{L} \frac{\partial T}{\partial y}\right|_{P}}{\left(T_{\text {Sat }}-T_{P}\right)}=\frac{\lambda_{L}}{\delta}$

In equation (21), $q$ it has been assumed positive for the condensation, therefore the energy balance can be written as:

$q=\left.\lambda_{L} \frac{\partial T}{\partial y}\right|_{P}=\frac{\lambda_{L}\left(T_{S a t}-T_{P}\right)}{\delta}=\left(r_{L V}\right) \frac{d G}{d x}$

Specifying the boundary condition on the wall gives the expression for an isothermal wall a $T_{P}$. Dipping the thickness $\delta$ in equation (20):

$\delta=\sqrt[3]{\frac{3}{4} \frac{\rho_{L} v_{L}^{2}}{\left(\rho_{L}-\rho_{V}\right) g} \frac{R e}{\sin \theta}}$

Substituting equations (11) and (12) into (20), we obtain that:

$\frac{2 \lambda_{L}\left(T_{S a t}-T_{S a t}\right) d}{\mu_{L}\left(r_{L V}\right)}\left(\frac{4}{3} \frac{\left(\rho_{L}-\rho_{V}\right) g}{\rho_{L} v_{L}^{2}}\right)^{1 / 3} \sin ^{1 / 3} \theta d \theta=\sqrt[3]{\operatorname{Re}} d R e$
Integrating in (22) with $\operatorname{Re}=0$ in $\theta=0$ and $\operatorname{Re}=\operatorname{Re}_{\pi}$ in $\theta=\pi$, we obtain that:

$R e_{\pi}=$
$\left[\left(\frac{4}{3}\right) \frac{2 \lambda_{L}\left(T_{S a t}-T_{S a t}\right) d}{\mu_{L}\left(r_{L V}\right)}\left(\frac{4}{3} \frac{\left(\rho_{L}-\rho_{V}\right) g}{\rho_{L} v_{L}^{2}}\right)^{1 / 3} \int_{0}^{\pi} \sin ^{1 / 3} \theta d \theta\right]^{3 / 4}$

A curious and important observation. It was given preference to use Re instead of thickness $\delta$ as an independent variable, the explanation is simple. $\operatorname{Re}=0$ in $\theta=0$ because, by symmetry, the velocity of the mass flow is zero at the top of the tube, while the thickness of the film in $\theta=0$ is finite and unknown [1], [3], [5], [7]. A global energy balance on the middle of the tube provides the average coefficient of heat transfer, so that:

$\bar{\alpha}\left(\frac{\pi d}{2}\right)\left(T_{S a t}-T_{P}\right)=G_{\pi}\left(r_{L V}\right)=\frac{\mu_{L}\left(r_{L V}\right) \mathrm{Re}_{\pi}}{4}$

Substituting the value of $\operatorname{Re}_{\pi}$ in equation (23) and rearranging gives:

$\bar{\alpha}=\left(\frac{4}{3 \pi}\right)\left(\frac{1}{2}\right)^{1 / 4}\left(\int_{0}^{\pi} \sin ^{1 / 3} \theta d \theta\right)^{3 / 4}\left(\frac{\left(\rho_{L}-\rho_{V}\right) g\left(r_{L V}\right) \lambda_{L}^{3}}{v_{L}\left(T_{S a t}-T_{p}\right) d}\right)^{1 / 4}$

The integral present in equation (25) can be solved by the known integration techniques, obtaining:

$\int_{0}^{\pi} \sin ^{n} x d x=\frac{\sqrt{\pi}}{2} \frac{\Gamma\left(\frac{n}{2}+0.5\right)}{\Gamma\left(\frac{n}{2}+1\right)} \quad$ for $n>-1$

In Eq. (26) $\Gamma\left(\frac{n}{2}+0,5\right)$ and $\Gamma\left(\frac{n}{2}+1\right)$ are gamma functions, with their particularities and special properties. For $n=1 / 3$

$\Gamma\left(\frac{n}{2}+0,5\right)=1,35411793$

$\Gamma\left(\frac{n}{2}+1\right)=0,92771933$

Substituting (27) and (28) into (26) yields:

$\int_{0}^{\pi} \sin ^{n} x d x=\frac{\sqrt{\pi}}{2} \frac{\Gamma\left(\frac{n}{2}+0.5\right)}{\Gamma\left(\frac{n}{2}+1\right)}=1.293554$

then:

$\int_{0}^{\pi} \sin ^{1 / 3} \theta d \theta=2 \int_{0}^{\pi / 2} \sin ^{1 / 3} \theta d \theta=2.5871095$

Substituting (29) into (25) yields:

$\alpha_{\text {Horiz }}=0,923\left(\frac{\left(\rho_{L}-\rho_{V}\right) g\left(r_{L V}\right) \lambda_{L}^{3}}{v_{L}\left(T_{S a t}-T_{p}\right) d}\right)^{1 / 4}$

The latent heat $\left(r_{L V}\right)$ in (30) is replaced by the Roshenow correction $\left(r_{L V}\right)$ ", which states that when there is a possibility 
of subcooling the liquid, the latent heat should be affected as follows [20-26]:

$$
\left(r_{L V}\right)^{\prime \prime}=\left(r_{L V}\right)+\frac{3}{8} C p_{L}\left(T_{S a t}-T_{P}\right)
$$

Substituting (31) into (30) yields:

$\alpha_{\text {Horiz }}=0,923\left(\frac{\lambda_{L}^{3}\left(\rho_{L}-\rho_{V}\right) g\left(r_{L V}+\frac{3}{8} C p_{L}\left(T_{S a t}-T_{p}\right)\right)}{v_{L}\left(T_{\text {Sat }}-T_{p}\right) d}\right)^{1 / 4}$

Finally, as it is a sloped surface, since the acceleration of gravity is present in the denominator is affected in the form of product by $\sin \phi$ (the sine of the angle formed with the horizontal), being in final:

$\alpha=0,923\left(\frac{\lambda_{L}^{3}\left(\rho_{L}-\rho_{V}\right) g \sin \phi\left(r_{L V}+\frac{3}{8} C p_{L}\left(T_{S a t}-T_{p}\right)\right)}{v_{L}\left(T_{S a t}-T_{p}\right) d}\right)^{1 / 4}$

Transforming mathematically expression (33) we arrive at:

$N u=0,923 \sqrt[4]{d^{3} \frac{\left(\rho_{L}-\rho_{V}\right) g \sin \phi\left(r_{L V}+\frac{3}{8} C p_{L}\left(T_{S a t}-T_{p}\right)\right)}{v_{L} \lambda_{L}\left(T_{S a t}-T_{p}\right) d}}$

\section{EXPERIMENTAL VALIDATION}

\subsection{Experimental validation of the new model}

All experimental data were taken from references $[1,4,6$, 10] which included data from water in diferent operational conditions for ACC systems. The pipe diameters considered range from 20 to $50 \mathrm{~mm}$; with mass fluxes from 2 to 75 $\mathrm{kg} / \mathrm{m}^{2} \mathrm{~s}$, and reduced pressures $P_{R}=P / P_{C}$ from 0.0008 to 0.11 . In all cases of subcooling the temperature of the liquid $T_{\text {subc }}$ has been included in the intervals $0,72 \cdot T_{\text {Sat }} \leq T_{\text {subc }}<T_{\text {Sat }}$, while the friction factor is evaluated for the two-phase by Martinelli equation [27-31].

In the model validation, the wall temperature is taken as the arithmetic mean of the temperatures at the entrance and the exit of the tube. With the professional software TkSolver 5.0, a comparative function can be executed, establishing a tolerance (permissible error) equal to $10^{-6}$ and using for the determination of the physical properties of water. The model IAPWS Formulation 1995 for the Thermodynamic Properties of Ordinary Water Substance For General and Scientific Use. The results obtained are plotted in Cartesian coordinates, taking as the axis of the ordinates the complex $\log (\operatorname{Re} \cdot \operatorname{Pr} \cdot f / 8)$ and the quotient (\%error/150) in $\mathrm{Y}$ ordinates.

The error committed with the use of equation (34) tends to decrease as the value of the complex $\log (\mathrm{Re} \cdot \mathrm{Pr}$. $f / 8$ ) increases, with a mean error equal to $12.86 \%$ for $\log (\operatorname{Re} \cdot \operatorname{Pr} \cdot f / 8)=3.5$ and a mean error equal to $8.75 \%$ to $\log (\operatorname{Re} \cdot \operatorname{Pr} \cdot f / 8)=5.08$

The tests performed also allow the expression (36) to correlate generally with an average order error $\pm 15,2 \%$ for $84.12 \%$ of the available experimental samples, as shown in figure 2 , itself was represented the Chato equation (37) by a red solid line.

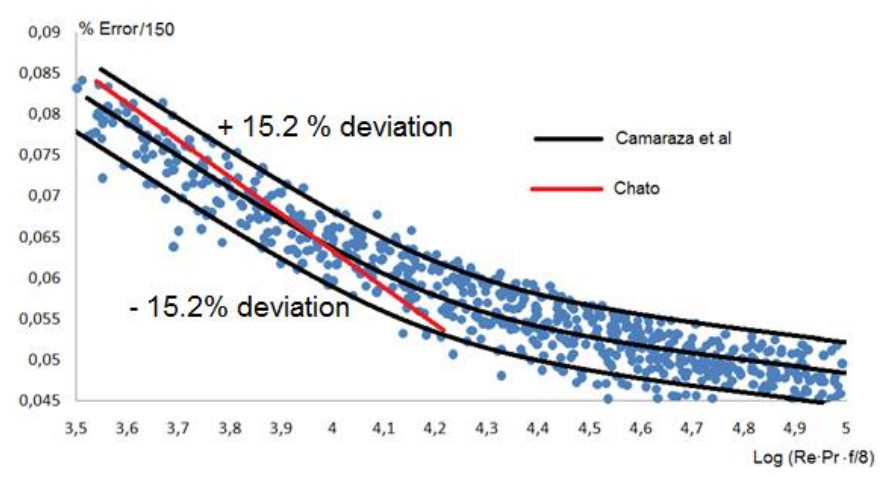

Figure 2. Graphic representation of the correlation errors of the expressions (34)

\section{CONCLUSIONS}

A model for the determination of the mean condensation heat transfer coefficient in ACC systems has been obtained analytically, which is valid for straight horizontal and inclined tubes, and has a higher adjustment to the model of greater diffusion in the known literature, The Chato equation, in the intervals $3.55 \leq \log (\operatorname{Re} \cdot \operatorname{Pr} \cdot f / 8) \leq 3.7$ and $4.14 \leq$ $\log (\operatorname{Re} \cdot \operatorname{Pr} \cdot f / 8) \leq 4.22$, but not in the interval $3.8 \leq$ $\log (\operatorname{Re} \cdot \operatorname{Pr} \cdot f / 8) \leq 4.05$ in which equation (34) presents a better fit to the available experimental data.

The new model obtained is valid for a larger range of the Re number $10^{3} \leq \operatorname{Re}_{L} \leq 2,5 \cdot 10^{5}$, unlike Chato equation which is only valid for $\operatorname{Re}_{L}<3,5 \cdot 10^{4}$, and generally correlates with a mean order error $\pm 15,2 \%$ for $84.12 \%$ of the available experimental samples, Surpassing the $18.2 \%$ error attributed to the Chato model given for his author, which coincides with the initial criterion of the investigation, considering that the objectives of the investigation are met. The authors consider that possible adjustments with new experimental quantities can reduce the correlation error in the interval $3.8 \leq$ $\log (\operatorname{Re} \cdot \operatorname{Pr} \cdot f / 8) \leq 4.05$.

\section{ACKNOWLEDGMENT}

The authors give special thanks to Dr. Neils Jhenki (University of California, Los Angeles), USA, for his assistance for this paper.

\section{REFERENCES}

[1] Dorao CA, Fernandhino M. (2017). Dominant dimensionless groups controlling heat transfer coefficient during flow condensation inside pipes. International Journal of Heat and Mass Transfer 112: 465-479.

https://doi.org/10.1016/j.ijheatmasstransfer.2017.04.104

[2] Boyko LD, Kruzhilin GN. (1967). Heat transfer and hydraulic resistance during condensation of steam in a horizontal tube and in a bundle of tubes. International Journal of Heat and Mass Transfer 10(3): 361-373. https://doi.org/10.1016/0017-9310(67)90152-4

[3] Kim SM, Mudawar I. (2013). Universal approach to predicting heat transfer coefficient for condensing mini/micro-channel flow. International Journal of Heat 
and Mass Transfer 56(1-2): 238-250 http://dx.doi.org/10.1016/j.ijheatmasstransfer.2012.09.0 32.

[4] Zhang H, Fang X, Shang H, Chen W. (2015). Flow condensation heat transfer correlations. International Journal of Refrigeration 59: 102-114. http://dx.doi.org/10.1016/j.ijrefrig.2015.07.013

[5] Shah MM. (1979). A general correlation for heat transfer during film condensation inside pipes. International Journal of Heat and Mass Transfer 22(4): 547-556. https://doi.org/10.1016/0017-9310(79)900589

[6] Rosson F. (1957). Heat transfer during condensation inside a horizontal tube. Ph.D. Thesis. Rice University. https://scholarship.rice.edu/handle/1911/18428, accessed on Jun. 21, 2017.

[7] Tandon TN, Varma HK, Gupta CP. (1995). Heat transfer during forced convection condensation inside horizontal tube. International Journal Refrigeration 18(3): 210-214. https://doi.org/10.1016/01407007(95)90316-R

[8] Dobson MK, Chato JC. (1998). Condensation in smooth horizontal tubes. Journal Heat Transfer 120(1): 193213, http://dx.doi.org/10.1115/1.2830043

[9] Cavallini A, Col DD, Doretti L, Matkovic M, Rossetto L, Zilio C, Censi G. (2006). Condensation in horizontal smooth tubes: a new heat transfer model for heat exchanger design. Heat Transfer Engineering 27(8):pp. 31-38. https://doi.org/10.1080/01457630600793970

[10] Bohdal T, Charun H, Sikora M. (2012). Heat transfer during condensation of refrigerants in tubular minichannels. Archives of Thermodynamics 33(2): 322. http://dx.doi.org/10.2478/v10173-012-0008-x

[11] Camaraza Y, (2017). Introducción a la Termotransferencia. Ed. Universitaria, 2017, La Habana, Cuba, ISBN: 978-959-16-3286-9. http://beduniv.reduniv.edu.cu/index.php?page $=3 \& \mathrm{id}=11$ $79 \& \mathrm{db}=0$ accessed on Jun. 21, 2017.

[12] Camaraza Y, Khandy NH, Cruz-Fonticiella OM, Garcia OF. (2017). Abstract of heat transfer coefficient modelation in single-phase systems inside pipes. Mathematical Modelling of Engineering Problems 4(3):132-136. https://doi.org/10.18280/mmep.040303

[13] Camaraza Y, Cruz-Fonticiella OM, Garcia OF. (2018). Obtención de un modelo para la determinación del coeficiente medio de transferencia de calor por condensación en sistemas ACC, Tecnología Química XXXVIII(1): 230-246 http://scielo.sld.cu/pdf/rtq/v38n1/rtq15118.pdf

[14] Lee H, Yoon J, Kim Y, Bansal PK. (2006). Condensing heat transfer and pressure drop characteristics of hydrocarbon refrigerants. International Journal of Heat and Mass Transfer 49: 1922-1927. https://doi.org/10.1016/j.ijheatmasstransfer.2005.11.008

[15] Yan Y, Lin T. (1999). Condensation heat transfer and pressure drop of refrigerant R-134a in a small pipe. International Journal of Heat and Mass Transfer 42: 697-708. 9310(98)00195-1

[16] Akers WW, Deans HA, Crosser OK. (1959). Condensing heat transfer within horizontal tubes. Chemical Engineering Progress Symposium Series 55(29) pp. 171-176.
[17] Lemmon EW, Huber ML, McLinden MO. (2013). NIST reference fluid thermodynamic and transport properties REFPROP, Tech. Rep.

[18] Tang CC. (2011). A study of heat transfer in nonboiling two-phase gas-liquid flow in tubes for horizontal, slightly inclined, and vertical orientations. Ph.D. Thesis. Oklahoma State University Publishing, 2011. Ar Xiv: 1011.1669v3. https://hdl.handle.net/11244/7820. accessed on Jun. 21, 2017.

[19] Mollamahmutoglu M. (2012). Study of isothermal pressure drop and non-boiling heat transfer in vertical downward two phase flow. Ms. Thesis. Oklahoma State University Publishing, https://pqdtopen.proquest.com/doc/1318673189.html?F MT=ABS, accessed on Jun. 21, 2017.

[20] Cavallini A, Censi G, Doretti, L, Longo GA, Rossetto L, Zilio C. (2003). Condensation inside and outside smooth and enhanced tubes - a review of recent research. International Journal of Refrigeration 26(4): 373-392. 7007(02)00150-0

[21] Wojtan L, Ursenbacher T, Thome J R. (2005). Investigation of flow boiling in horizontal tubes: Part II. Development of a new heat transfer model for stratifiedwavy, dryout and mist flow regimes. International Journal of Heat and Mass Transfer 48(14): 2970-2985. https://doi.org/10.1016/j.ijheatmasstransfer.2004.12.013

[22] Rifert VG, Sereda VV. (2015). Condensation inside Smooth horizontal tubes: Part 1. Survey of the methods of heat-exchange prediction. Thermal Science 19(5): 1769-1789. https://doi.org/10.2298/TSCI140522036R

[23] Thome JR. (2005). Condensation in plain horizontal tubes: recent advances in modelling of heat transfer to pure fluids and mixtures. Journal of the Brazilian Society of Mechanical Sciences and Engineering 27(1): 23-30, 58782005000100002

[24] Cttani L, Bozzoli F, Raineri S. (2017). Experimental study of the transitional flow regime in coiled tubes by the estimation of local convective heat transfer coefficient. International Journal of Heat and Mass Transfer 112: 825-836. https://doi.org/10.1016/j.ijheatmasstransfer.2017.05.003

[25] Bhagwat SM, Ghajar AJ. (2016). Experimental investigation of non-boiling gas-liquid two phase flow in upward inclined tubes. Experimental Thermal and Fluid Science 79: 301-318. https://doi.org/10.1016/j.expthermflusci.2016.08.004

[26] Derby M, Joon H, Peles Y, Jensen MK. (2011). Condensation heat transfer in square, triangular, and semi-circular mini-channels. International Journal of Heat and Mass Transfer 55(3): 187-197. https://doi.org/10.1016/j.ijheatmasstransfer.2011.09.002

[27] Nasser I, Duwairi HM. (2016). Thermal dispersion effects on convection heat transfer in porous media with viscous dissipation. International Journal of Heat and Technology 34(2): 207-212. http://doi.org/10.18280/ijht.340208

[28] Pourmahmoud N, Abbaszadeh M, Rashidzadeh M. (2016). Numerical simulation of effect of shell heat transfer on the vortex tube performance. International Journal of Heat and Technology 34(2): 293-301. http://doi.org/10.18280/ijht.340220 
[29] Zhang ZY, Yang JG. (2015). The effect of face-air velocity distribution on heat transfer performance of aircooled condensers. International Journal of Heat and Technology 33(1):

55-62. http://doi.org/10.18280/ijht.330108

[30] Zhan NY, Xu Y, Wang ZY. (2015). Research on heattransfer and three-dimensional characteristics of natural convection in a small cavity with heat sources. International Journal of Heat and Technology 33(3): 5966. http://doi.org/10.18280/ijht.330308

[31] Priyam A, Chand P. (2017). Heat transfer and pressure drop characteristics of wavy fin solar air heater. International Journal of Heat and Technology 35(4): 1015-1022. http://doi.org/10.18280/ijht.350438

\section{NOMENCLATURE}

G Mass flux, $\mathrm{kg} \cdot \mathrm{m}^{-2} \cdot \mathrm{s}^{-1}$

$\mathrm{Cp} \quad$ Specific heat, $\mathrm{J}_{\mathrm{kg}} \mathrm{kg}^{-1} \cdot \mathrm{K}^{-1}$

$\mathrm{d} \quad$ Inner equivalent tube diameter, $\mathrm{m}$

g gravitational acceleration, $\mathrm{m} \cdot \mathrm{s}^{-2}$

Re Reynolds number

$\mathrm{Nu} \quad$ Nusselt number

Pr Prandtl number

$\operatorname{Pr}_{\mathrm{L}} \quad$ Prandtl number for single-phase

$\mathrm{P} \quad$ Fluid pressure, $\mathrm{kg} . \mathrm{m}^{-1} \cdot \mathrm{s}^{-2}$

X Steam quality
$\left(r_{L V}\right) \quad$ Latent heat of vaporization, $\mathrm{J} . \mathrm{kg}^{-1} \cdot \mathrm{K}^{-1}$

$\mathrm{T}_{\text {sat }} \quad$ Saturation temperature, ${ }^{0} \mathrm{C}$

$\mathrm{T}_{\mathrm{P}} \quad$ Wall temperature, ${ }^{0} \mathrm{C}$

$\mathrm{N} \quad$ Numbers of experimental points.

\section{Greek symbols}

$\alpha \quad$ two-phase heat transfer coefficient, $\mathrm{kg} \cdot \mathrm{m}^{-2} \cdot \mathrm{s}-3 \cdot \mathrm{K}^{-1}$

$\bar{\alpha} \quad$ Mean heat transfer coefficient, $\mathrm{kg} \cdot \mathrm{m}^{-2} \cdot \mathrm{s}-3 \cdot \mathrm{K}^{-1}$

$\delta \quad$ Thickness film, m

$\alpha_{\mathrm{T}} \quad$ Two-phase heat transfer coefficient, kg.m ${ }^{-2} . \mathrm{s}-3 . \mathrm{K}^{-1}$

$\theta_{\text {med }} \quad$ Inscript pipe angle,

$\mu \quad$ Dynamic viscosity, $\mathrm{kg} . \mathrm{m}^{-1} \cdot \mathrm{s}^{-1}$

$\mu_{\mathrm{L}} \quad$ Liquid dynamic viscosity, $\mathrm{kg} \cdot \mathrm{m}^{-1} \cdot \mathrm{s}^{-1}$

$\mu_{\mathrm{V}} \quad$ Steam dynamic viscosity, $\mathrm{kg} . \mathrm{m}^{-1} \cdot \mathrm{s}^{-1}$

$\rho_{\mathrm{L}} \quad$ Density of liquid, kg.m-3

$\rho_{\mathrm{v}} \quad$ Density of vapor, kg.m-3

$\lambda \quad$ Fluid thermal conductivity, $\mathrm{W} \cdot \mathrm{m}^{-1} \cdot \mathrm{K}^{-1}$

$v_{\mathrm{L}} \quad$ Liquid kinematic viscosity, $\mathrm{m} 2 . \mathrm{s}^{-1}$

$\Delta \mathrm{T}$ Temperature difference across the condensate film, $\mathrm{K}$

\section{Subscripts}

Eq. Equation 